\title{
Improvement of algorithms for voltage circuits fault detection in relay protection terminal of 6-35 $\mathrm{kV}$ electrical networks
}

\author{
Vladimir Vukolov', Mikhail Obalin ${ }^{1}$, Anton Petrov ${ }^{2, *}$ \\ ${ }^{1}$ R. E. Alekseev Nizhnii Novgorod State Technical University, 603950, Minin Str. 24, Nizhnii Novgorod, Russia \\ ${ }^{2} J S C$ NIPOM, advanced development department, 603140, Lenin Ave., 20, Nizhnii Novgorod, Russia
}

\begin{abstract}
Issues of increase of consumer power supply reliability by prevention of protection device false operation and unreasonable tripping of the protected network element at malfunction of measuring voltage transformer secondary circuits are considered. Options for implementation in relay protection microprocessor terminals of advanced blocking algorithms in case of voltage circuits fault are proposed.
\end{abstract}

\section{Introduction}

Reliability, along with speed of response, sensitivity and selectivity, is the main characteristic of relay protection devices. Reliability of modern microprocessing terminals of relay protection devices is understood so that the protection device should operate at all types of damages provided by design and should not-operate in all other cases for which protection with this device is not provided. Unreliable relay protection device itself becomes a source of accidents, and false triggering of protective relays lead to unreasonable network tripping which leads to economic losses due to production or technological failures.

Damages to the voltage transformer circuits leads to a false triggering of relay protection devices, which use the voltage signal. Fault detection in the measuring transformer circuits is carried out automatically using the voltage circuit lock function.

Voltage transformer secondary circuit damages are short circuit and a circuit interruption. To protect a measuring transformer against short-circuit overcurrent, circuit breakers or fuses which disconnect the damaged circuit can be added into its secondary circuits. The very moment of damage and subsequent triggering of the circuit breakers or fuses lead to distortion of voltage signal and improper operation by relay protection devices. Primary circuits' interruption without short circuit is also a kind of voltage transformer damage. A fact of voltage circuits' damage should be detected by voltage circuit lock function which sends a fault signal and blocks operation of relay protection device which use information from the voltage measuring elements.

\section{Connection of relay protection \\ 2 Connection of relay protection secondary circuits}

\footnotetext{
* Corresponding author: petrov85@inbox.ru
}

In practice, relay protection devices can be connected to secondary windings of voltage transformers worked in the network with isolated neutral in several ways (Fig. 1) depending on the scheme of secondary voltage circuits at the substation and necessity of information about the signal parameters (Table 1).

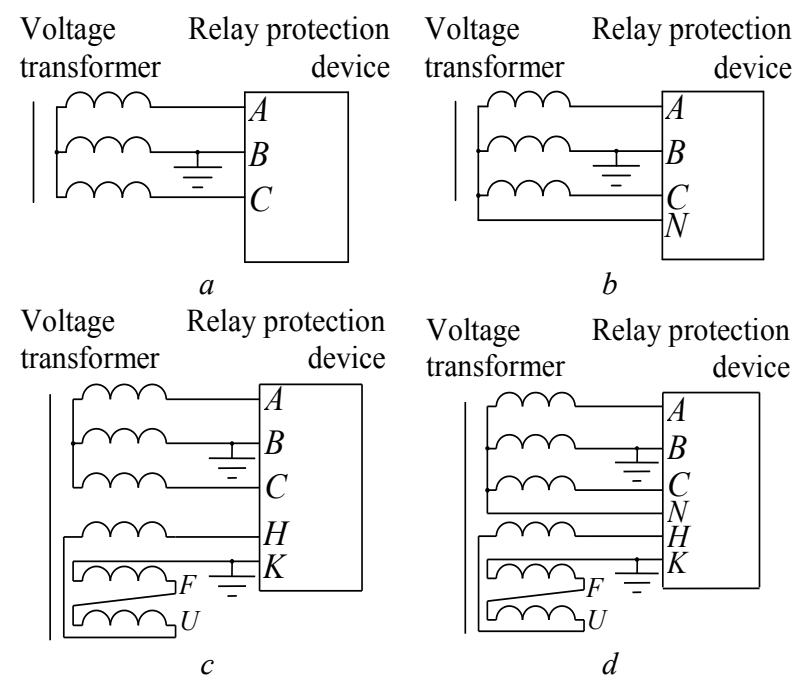

Fig. 1. Connection of relay protection terminal to secondary voltage circuits: $a-\mathrm{A}, \mathrm{B}, \mathrm{C}$ phases; $b-\mathrm{A}, \mathrm{B}, \mathrm{C}$ phases with $\mathrm{N}$ neutral conductor; $c-\mathrm{A}, \mathrm{B}, \mathrm{C}$ phases and circuits of open delta circuit $\mathrm{H}, \mathrm{K} ; d-\mathrm{A}, \mathrm{B}, \mathrm{C}$ phases with $\mathrm{N}$ neutral conductor and circuits of open delta circuit $\mathrm{H}, \mathrm{K}$

Positive and negative sequence of phase-to-ground voltages, and also phase-to-phase voltage values, can be reached for any type of terminal connecting to the Ywinding circuit of transformer secondary voltage (Fig. 1). Zero sequence measurement is carried out through outputs $\mathrm{H}$ and $\mathrm{K}$ of additional open delta winding (Fig. $1, c, d)$. Calculation of zero sequence value and measurement of phase-to-ground voltages are possible when the terminal is connected to output $\mathrm{N}$ of $\mathrm{Y}$-circuits (Fig. 1, b, d). 
Table 1. Connection of relay protection terminals to voltage transformer secondary circuits

\begin{tabular}{|c|c|c|c|c|}
\hline \multirow{2}{*}{$\begin{array}{l}\text { Voltage signal } \\
\text { characteristic value }\end{array}$} & \multicolumn{4}{|c|}{$\begin{array}{l}\text { Connection to voltage } \\
\text { transformer circuits }\end{array}$} \\
\hline & A,B,C & $\underset{\mathbf{N}}{\mathbf{A}, \mathbf{B}, \mathbf{C},}$ & $\begin{array}{c}\mathbf{A}, \mathbf{B}, \mathbf{C}, \\
\mathbf{H}, \mathbf{K}\end{array}$ & $\begin{array}{l}\mathbf{A}, \mathbf{B}, \mathbf{C}, \\
\mathbf{N}, \mathbf{H}, \mathbf{K}\end{array}$ \\
\hline Phase-to-ground value & - & + & + & + \\
\hline Phase-to-phase value & + & + & + & + \\
\hline Positive sequence & + & + & + & + \\
\hline Negative sequence & + & + & + & + \\
\hline Calculated zero sequence & - & + & - & + \\
\hline Measured zero sequence & - & - & + & + \\
\hline
\end{tabular}

Note. To measure zero sequence voltage, $\mathbf{H}$ and $\mathbf{K}$ circuits are used as open delta winding terminals.

\section{Existing algorithms for detecting damage to voltage transformer circuits}

Currently, two algorithms to detect damages in voltage transformer circuits are widely used in practice $[1,2]$ :

1. Comparison of zero sequence voltages, one of which is measured at open delta winding of voltage transformer, and another is calculated by vector adding of Y-winding phase-to-ground voltages. It is obvious that, at this approach implementation, relay protection terminal requires connection to all secondary circuits of the voltage transformer (Fig. 1, d). Its serious drawback is the fundamental inability to detect damage in the primary circuits of measuring voltage transformer.

2. Change monitoring in voltage circuits in the change absence in current circuits. One of conditions for protecting device triggering is asymmetry in voltage circuits (negative or zero sequence voltages) while current circuits are symmetric. The second condition is loss of voltage in all three phases in the absence of shortterm asymmetry in current circuits that appears even at symmetrical three-phase metal short circuit [3]. This algorithm can be implemented for any variant of terminal connection to secondary voltage circuits of voltage transformer, but impossibility to calculate some parameters of the signal (for example, zero sequence voltage at absence of $\mathrm{Y}$-winding $\mathrm{N}$ conductor) limits its application. The undoubted advantage of the approach is possibility to detect damages, including those in primary circuits of voltage transformer. Its implementation additionally requires a signal from current transformers.

\section{Identifying voltage transformer circuit damage for various ways of terminal connecting}

Capabilities of microprocessor-based relay protection devices allow implementing both approaches for identifying damage, and this is why automation equipment can fully control status of phase conductors of voltage transformer circuits. Depending on operating mode, requirements to protection of a particular connection, structure of secondary voltage networks, etc. Voltage circuit lock function is able to work in accordance with any of mentioned approaches both individually and simultaneously.

Up-to-date relay protection and automation devices usually have symmetrical input resistance. This preconditions certain features at detection of some types of voltage circuit damages. Reaction of the algorithms on typical faults in the voltage transformers circuits is given in tables 2, 3 .

Table 2. Action of the algorithm which compares calculated and measured zero sequence voltage at various faults in voltage transformer's circuits

\begin{tabular}{|l|l|c|}
\hline \multicolumn{1}{|c|}{ Damage } & $\begin{array}{c}\text { Required } \\
\text { action }\end{array}$ & $\begin{array}{c}\text { Characterization } \\
\text { of the action }\end{array}$ \\
\cline { 3 - 3 } & $\mathbf{A}, \mathbf{B}, \mathbf{C}, \mathbf{N}, \mathbf{H}, \mathbf{K}$ \\
\hline $\begin{array}{l}\text { Phase interruption of } \\
\text { secondary Y-winding }\end{array}$ & Operation & True \\
\hline $\begin{array}{l}\text { Two phases interruption of } \\
\text { secondary Y-winding }\end{array}$ & Operation & True \\
\hline $\begin{array}{l}\text { Phase and zero conductor } \\
\text { interruption of secondary Y- } \\
\text { winding }\end{array}$ & Operation & True \\
\hline $\begin{array}{l}\text { Opening of Y-winding circuit } \\
\text { breaker }\end{array}$ & Operation & True \\
\hline $\begin{array}{l}\text { Short-circuit of phase and zero } \\
\text { conductors of secondary Y- } \\
\text { winding }\end{array}$ & Operation & True \\
\hline $\begin{array}{l}\text { Two-phase short circuit of } \\
\text { secondary Y-winding with } \\
\text { circuit breaker opening }\end{array}$ & Operation & True \\
\hline $\begin{array}{l}\text { Three-phase short circuit of } \\
\text { secondary Y-winding with } \\
\text { circuit breaker opening }\end{array}$ & Operation & True \\
\hline $\begin{array}{l}\text { Zero conductor interruption of } \\
\text { secondary Y-winding }\end{array}$ & Operation & False \\
\hline $\begin{array}{l}\text { Phase interruption of voltage } \\
\text { transformer primary circuit }\end{array}$ & Operation & False \\
\hline $\begin{array}{l}\text { Single-phase earthing in the } \\
\text { primary network }\end{array}$ & Disregard & True \\
\hline $\begin{array}{l}\text { Short circuit of two voltage } \\
\text { transformer phases in the } \\
\text { primary circuit }\end{array}$ & Disregard & True \\
\hline
\end{tabular}

Note. "True" value corresponds to voltage circuit lock function behaviour complying with the requirements. "False" value corresponds to incorrect voltage circuit lock function action.

Due to symmetry of input impedance of relay protection device voltage circuits, in normal electrical network operation, zero conductor interruption will not cause changes in symmetrical voltage components and this will not allow working of voltage circuit lock function at such damage (Tables 2, 3). If it is necessary to control the neutral conductor integrity, asymmetry of input resistance should be created artificially, for example, by connecting, in general, of three different resistors between neutral and phase conductors of the device terminals (Fig. 2). In this case, breakage of zero wire will be accompanied by a neutral shift in Y-winding circuit to the point defined by the resistances relations and appearance of zero sequence design voltage, which is calculated as geometric sum of its phase voltages. This phenomenon will cause voltage circuit lock function triggering when using either of two approaches: in the case of comparison of zero sequence calculated and 
measured values a difference between these values will appear which is a condition for the algorithm operation; appearance of zero sequence voltage in $\mathrm{Y}$-winding in the absence of disturbances in the current circuits is a prerequisite for operation of the second mentioned approach.

Table 3. Action of change monitoring in voltage circuits in the change absence in current circuits

\begin{tabular}{|c|c|c|c|c|c|}
\hline \multirow{2}{*}{ Damage } & \multirow{2}{*}{$\begin{array}{c}\text { Required } \\
\text { action }\end{array}$} & \multicolumn{4}{|c|}{$\begin{array}{c}\text { Characterization of the } \\
\text { action }\end{array}$} \\
\hline & & $\mathbf{A}, \mathbf{B}, \mathbf{C}$ & \begin{tabular}{|c|}
$\mathbf{A}, \mathbf{B}, \mathbf{C}$, \\
$\mathbf{N}$ \\
\end{tabular} & $\begin{array}{c}\mathbf{A}, \mathbf{B}, \mathbf{C} \\
\mathbf{H}, \mathbf{K}\end{array}$ & $\begin{array}{l}\mathbf{A}, \mathbf{B}, \mathbf{C}, \\
\mathbf{N}, \mathbf{H}, \mathbf{K}\end{array}$ \\
\hline $\begin{array}{l}\text { Phase interruption of } \\
\text { secondary Y- } \\
\text { winding }\end{array}$ & Operation & True & True & True & True \\
\hline $\begin{array}{l}\text { Two phases } \\
\text { interruption of } \\
\text { secondary Y- } \\
\text { winding }\end{array}$ & Operation & True & True & True & True \\
\hline $\begin{array}{l}\text { Phase and zero } \\
\text { conductor } \\
\text { interruption of } \\
\text { secondary Y- } \\
\text { winding }\end{array}$ & Operation & - & True & - & True \\
\hline $\begin{array}{l}\text { Opening of Y- } \\
\text { winding circuit } \\
\text { breaker }\end{array}$ & Operation & True & True & True & True \\
\hline $\begin{array}{l}\text { Short-circuit of } \\
\text { phase and zero } \\
\text { conductors of } \\
\text { secondary Y- } \\
\text { winding }\end{array}$ & Operation & - & True & - & True \\
\hline $\begin{array}{l}\text { Two-phase short } \\
\text { circuit of secondary } \\
\text { Y-winding with } \\
\text { circuit breaker } \\
\text { opening }\end{array}$ & Operation & True & True & True & True \\
\hline $\begin{array}{l}\text { Three-phase short } \\
\text { circuit of secondary } \\
\text { Y-winding with } \\
\text { circuit breaker } \\
\text { opening }\end{array}$ & Operation & True & True & True & True \\
\hline $\begin{array}{l}\text { Zero conductor } \\
\text { interruption of } \\
\text { secondary Y- } \\
\text { winding }\end{array}$ & Operation & - & False & - & False \\
\hline $\begin{array}{l}\text { Phase interruption of } \\
\text { voltage transformer } \\
\text { primary circuit }\end{array}$ & Operation & True & True & True & True \\
\hline $\begin{array}{l}\text { Single-phase } \\
\text { earthing in the } \\
\text { primary network }\end{array}$ & Disregard & True & True & True & True \\
\hline $\begin{array}{l}\text { Short circuit of two } \\
\text { voltage transformer } \\
\text { phases in the } \\
\text { primary circuit }\end{array}$ & Disregard & True & True & True & True \\
\hline
\end{tabular}

Note. "True" value corresponds to voltage circuit lock function behaviour complying with the requirements. "False" value corresponds to incorrect voltage circuit lock function action. Dash means impossibility of this type of damage to exist in the considered system of secondary voltage circuits.

Use of open delta scheme to provide measured zero sequence voltage and its further use in relay protection algorithms imposes the need to monitor state of the conductors and this winding. As a solution to this problem for medium voltage networks, connection to $\mathrm{U}$ conductor of additional voltage transformer winding (Fig. 1,d) with monitoring and comparison of voltages between voltage transformer $\mathrm{K}$ and $\mathrm{U}$ phases, and between $\mathrm{H}$ and $\mathrm{U}$, can be use, similarly to110-220 kV networks [4]. However, design of three-phase voltage transformers which are most common used in networks with isolated neutral does not allow installation at substation of additional $U$ voltage busbar due to lack of output of this winding [5].

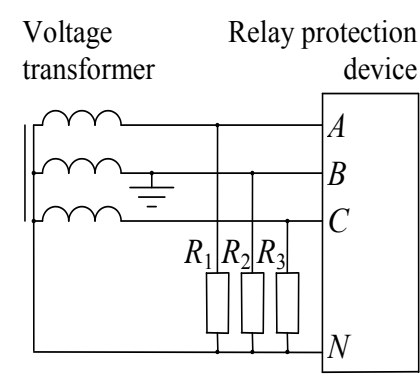

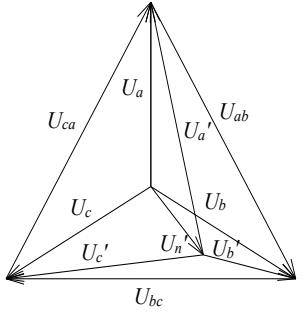

$b$
Fig. 2. Connection of additional resistors: $a$ - wiring diagram; $b$ - neutral shift in $\mathrm{Y}$-winding at zero conductor disconnection; $\mathrm{U}_{\mathrm{i}}$ - phase voltages at normal network operation; $\mathrm{Ui}_{\mathrm{i}}^{\prime}$ - phase voltages at zero conductor discontinuity; $\mathrm{U}_{\mathrm{ij}}$ - interphase voltages; $\mathrm{R}_{\mathrm{i}}$ - additional resistance connected to the phase voltage; $\mathrm{U}_{\mathrm{n}}{ }^{\prime}$ - position of the shifted neutral

Thus, if it is necessary to use zero sequence voltage in logic of relay protection device, it is advisable to define it by calculating phase voltages of $\mathrm{Y}$-winding voltage transformer. In this case, measured zero sequence signal of open delta winding will be used only to monitor the state of $\mathrm{Y}$-winding $\mathrm{N}$ conductor.

\section{Feature of operation of isolated neutral networks}

One of the features of $6-35 \mathrm{kV}$ electrical networks working with isolated neutral is that the neutral point position is defined by capacitance conductivities of each of the three phases and is virtually the same for the entire network [6]. If the power source of this network operates with unloaded buses or short network, the neutral conductor shift can occur due to asymmetric position of conductors, both relative to the ground and relative to each other. Another reason for the neutral point shift may be non-simultaneous switching of the switch phases that leads to saturation of voltage transformer magnetic circuit and ferroresonance processes with asymmetric change in phase conductivities relative to the ground of the measuring transformer [7,8].

At such operation modes, zero sequence voltage appears even in the absence of any damage to the network, to what the device protecting against singlephase earth faults reacts as on grounding fault while actually there is not an accident. This phenomenon is called "false earthing". 


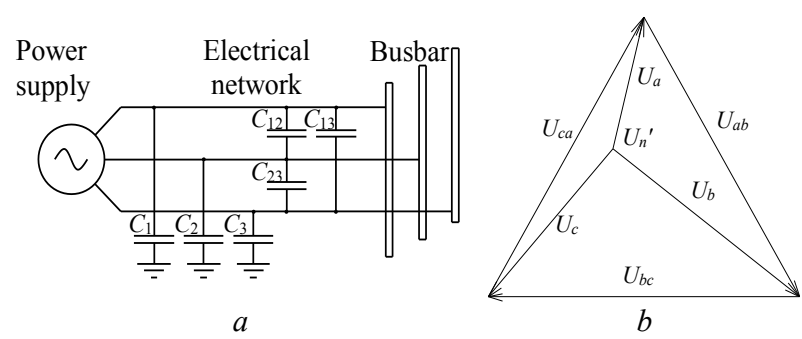

Fig. 3. Operation of the power supply with unloaded buses: a electrical circuit; $b$ - vector voltage diagram; $\mathrm{Ci}$ - capacitance of the phase relative to the ground; $\mathrm{Cij}$ - capacitance between two phases; Ui - phase voltage; Uij - interphase voltage; Un' shifted neutral position

Algorithms used in different approaches of voltage circuit lock function implementation behave differently when a "false earthing" appears in the electrical network. Erroneous work of the algorithm based on comparison of zero sequence measured and a calculated value when a "false earthing" appears is excluded. This is due to the fact that zero sequence voltage appears in both secondary windings of the voltage transformer and difference between them is minimal. On the contrary, without additional modifications, algorithm, which controls disturbances in the current and voltage circuits, will work erroneously and will block part of the protection and automation devices.

\section{Improvements of voltage circuit lock function}

As mentioned above, the neutral shift and appearance of zero sequence voltage in $6-35 \mathrm{kV}$ electrical networks is possible even in the absence of damage. Strictly speaking, this mode is not normal, but voltage circuit lock function should not react to it due to lack of damage in the voltage transformer circuits. The simplest way to improve the voltage circuit lock function algorithms is to cancel zero sequence check in secondary voltage circuits for the approach based on change monitoring in voltage circuits in the change absence in current circuits. In this case, simultaneous action in relay protection device of both approaches will allow identifying all damages in the voltage transformer circuits, provided that terminal connection scheme shown in Fig. 1, $d$ is used. It is worth noting that application of the voltage circuit lock function approach, which compares measured and calculated zero sequence values of, is possible only for this secondary circuit's scheme.

Application of the secondary voltage circuit diagram shown in Fig. 1, in which terminals of open delta winding are not used, requires revision. Connecting asymmetric resistor system, which causes a neutral shift at zero conductor discontinuity (Fig. 2), will result in zero sequence voltage. Moreover, due to symmetry of the voltage inputs, the neutral point shift value at zero conductor discontinuity will be defined by the resistors parameters and will be positioned in a well-defined point on voltage vector diagram. This fact can be used to detect damage to zero conductor in the $\mathrm{Y}$-windings. The logic diagram of the block, which is created using this proposal, is shown in Fig. 4. Detection of zero conductor discontinuity will be carried out at zero sequence voltage jump (operation of zero sequence pulse starting element) with shift of neutral to the complex plane defined by setpoints (operation of $U_{n}$ ' pulse starting element), at that changes in the symmetrical current components should not occur (non-operation of $\mathrm{dI}_{1}, \mathrm{dI}_{2}, \mathrm{dI}_{0}$ pulse starting elements). The algorithm reset is carried out when the neutral point leaves the specified area (return of $\mathrm{U}_{\mathrm{n}}{ }^{\prime}$ starting element). The algorithm work is shown in Fig. 5, 6.

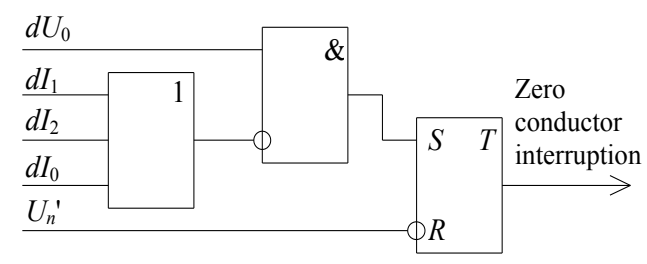

Fig. 4. Detection of zero conductor discontinuity in $\mathrm{Y}$ windings voltage transformer circuits: $\mathrm{dU} 0$ - element for starting change in zero sequence voltage; dI1, dI2, dI0 element for starting change of respective sequences current; Un' - element for starting calculation of neutral shift to a point defined by a set of asymmetrical resistances
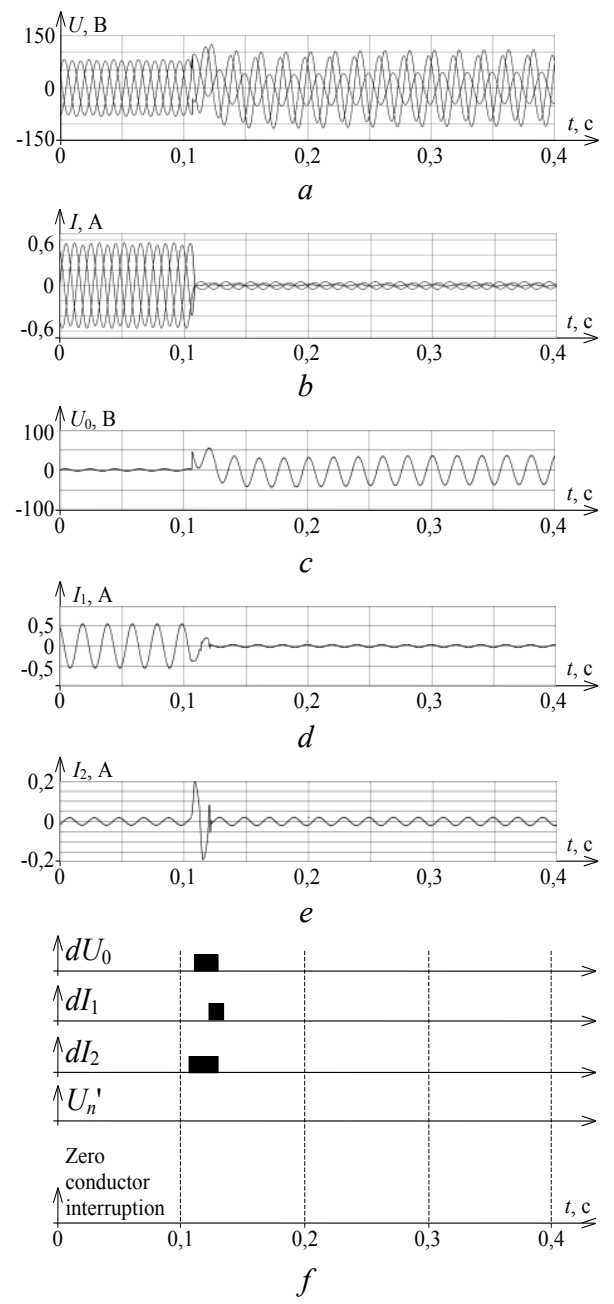

Fig. 5. Action of the algorithm to high-voltage network neutral shift in the unloaded buses operation mode: a - secondary voltage; $b$ - secondary current; $\mathrm{c}$ - zero sequence voltage; $d$ direct sequence current; e - reverse sequence current; $f$ - logic of operation 


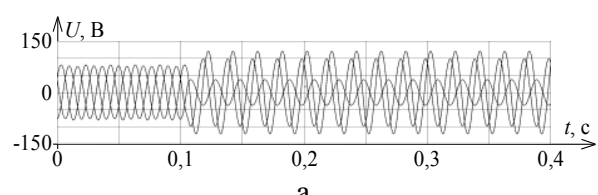

a
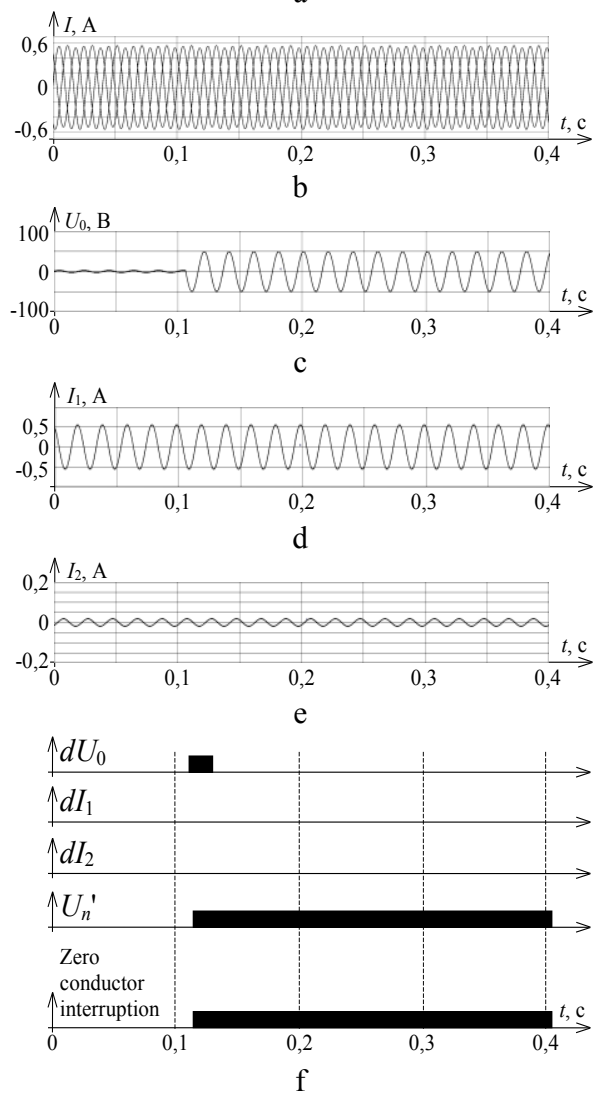

Fig. 6. Action of the algorithm to interruption of zero conductor in secondary $\mathrm{Y}$-windings $\mathrm{a}$ - secondary voltage; $\mathrm{b}$ secondary current; $\mathrm{c}$ - zero sequence voltage; $\mathrm{d}$-direct sequence current; $\mathrm{e}$ - reverse sequence current; $\mathrm{f}$ - logic of operation

Application of secondary circuit voltage diagram shown in Fig. 1, c, which uses open delta winding to define zero sequence values, is impractical due to the need for additional control of its circuit's state.

Use of the scheme shown in Fig. 1, $a$ requires no modification, but has a limitation on application because it does not allow defining a zero sequence voltage.

\section{Conclusion}

Analysis of secondary voltage schemes and fault detection algorithms for such circuits allows drawing the following conclusions:

1. Application areas of fault detection algorithms are defined for different variants of secondary voltage circuits schemes used at substations.

2. Use of the open delta winding is advisable only when implementing the algorithm comparing zero sequence voltages in star and open delta circuits.

3. To detect disconnection of star circuit neutral conductor, it is proposed to create an artificial asymmetry in the input circuits of relay protection device and to develop group of starting elements, which will analyses shift of the neutral position in the complex plane of voltages.

This work was supported by the Ministry of Science and Higher Education of the Russian Federation (agreement No. 075-15-2019-1209 of May 31, 2019. Unique project identifier RFMEFI57717X0244).

\section{References}

1. S. Ya. Petrov, Releyshik J., 1(6), 49 (2010).

2. D. Gallyamov, A. Mikhailov, Elektroenergetika glazami molodezhi J., IV, 129 (2015).

3. D. N. Kokoulin, V. A. Shuin, Vestnik ISPU J., 3, 18 (2012).

4. N. A. Doni, A. V. Sdobin, Releyshik J., 4(5), 73 (2009).

5. V. S. Fishman, News Elteh J., 6, 32-35 (2010).

6. V. A. Shuin, A, V. Gusenkov, Bibliotechka elektrotekhnika J., 11, 104 (2001).

7. N. A. Kolechitskaya, N. S. Lazarev, R. N. Shulga, K. A. Zmieva, Russian Electrical Engineering J., 4, 2 (2013).

8. A. Yu. Emel'yantsev, News Elteh J., 4, 34 (2009). 